•保护论坛・

\title{
中国国家公园体制改革：回顾与前瞻
}

\author{
王 毅 $1,2^{*}$ 黄宝荣 ${ }^{1}$ \\ 1 (中国科学院科技战略咨询研究院, 北京 100190) \\ 2 (中国科学院大学公共政策与管理学院, 北京 100049)
}

\begin{abstract}
摘要：自2013年提出建立国家公园体制，我国国家公园体制改革已取得了重要进展，成为整个生态文明体制改革 任务中进展最快、成果最显著的综合性改革。过去5年, 通过国家公园体制改革试点, 初步完成了国家公园的顶层 设计、明确了管理体制、启动了相关立法程序, 筑就了国家公园建设的基本框架。改革的主要经验可以总结为四 个方面: 一是高层引领与改革创新, 二是试点先行和动态调整, 三是问题导向和顶层设计, 四是利益相关方参与 和改善治理体系。然而，未来国家公园体制建设仍然任重道远，面临众多挑战和困难，包括国家公园建设区通常人 口众多、土地权属复杂、利益相关者众多、缺乏多方参与机制、地方管理能力薄弱等。今后, 应在总结国家公园 体制改革经验的基础上，坚持正确的改革取向，进一步扩大开放和创新思维，坚持法治优先、系统推进、分类指导、 分阶段实施的基本原则, 采取顶层设计加试点先行的方式, 实现依法办园、科学办园、民主办园、开放办园; 加快 推动国家公园和自然保护地立法，建立国家公园现代化治理体系，探索建立国家公园生态产品价值实现机制; 最 终使以国家公园为主体的自然保护地体系得到整体保护，人民利益得以最大化，真正实现人与自然和谐发展。
\end{abstract}

关键词：国家公园体制改革; 回顾与展望; 经验、问题与挑战; 建议

\section{Institutional reform for building China's national park system: Review and prospects}

\author{
Yi Wang ${ }^{1,2^{*}}$, Baorong Huang ${ }^{1}$ \\ 1 Institutes of Science and Development, Chinese Academy of Sciences, Beijing 100190 \\ 2 School of Public Policy and Management, University of Chinese Academy of Sciences, Beijing 100049
}

\begin{abstract}
Since the concept of National Park in China was put forward in 2013, the institutional reform for building China's national park system has made important progress and become the fastest and the most iconic comprehensive reform in the entire reform of the ecological civilization system. In the past five years, China has completed a top-down design, clarified a management system, initiated relevant legislative procedures, and built the basic framework for national park system through pilot programs. There are four important experiences in the institutional reform. The first is the combination of high-level leadership and system innovation. The second is pilot first followed by dynamic adjustment. The third is the problem oriented and top-down design. The fourth is encouraging stakeholder participation to improve governance system. Though progress has been made, the reform still faces many challenges and difficulties, and has a long way to go. National park potential construction areas often have large populations, complex land ownership patterns, numerous stakeholders, lack of multi-participation mechanisms, and weak local management capabilities. In the future, based on the experiences of institutional reform, we should insist on the correct reform orientation, further expand openness and innovate thinking, and follow the basic principles of system promotion, classification guidance, and phased implementation. We should combine top-down design with pilot programs, to establish national park system legally, scientifically, democratically and openly, to accelerate national park legislation, to establish a modern governance system, and to explore value realization mechanism of ecological products produced in national parks. In this way, the natural protected areas system with national parks as the backbone will be protected as a whole, the interests of the people will be maximized, and the harmonious development between man and nature will be realized.
\end{abstract}

* 通讯作者 Author for correspondence. E-mail: wangyi@casipm.ac.cn 
Key words: institutional reform for national park; review and prospects; experience, problems and challenges; recommendations

经过60多年的努力, 我国已经建立了数量众 多、类型丰富、功能多样的自然保护地体系。虽然 保护地的数量和面积快速增长, 但保护质量不高, 保护模式有待转型(王毅, 2017)。党的十八届三中全 会提出建立国家公园体制, 希望借此破解保护地长 期面临的问题。2015年1月, 国家发展和改革委员会 等十三个部门联合发布了《建立国家公园体制试点 方案》，拉开了国家公园体制改革的序幕。五年来, 我国国家公园体制改革在各方共同努力下，树立理 念、厘清方向, 逐步达成共识, 取得了重要进展, 但 仍面临一些问题和挑战, 需要通过深化改革、扩大 开放和持续创新予以解决。本文希望通过总结国家 公园体制改革的成功经验, 分析改革开放再出发所 面临的问题和挑战，在此基础上提出深化体制改革 的建议, 为建立符合中国国情、保护优先、让人民 满意的国家公园提供参考。

\section{1 国家公园体制改革的进展和经验}

自2013年党的十八届三中全会决议提出建设 国家公园体制, 特别是2015年启动国家公园体制试 点以来, 国家公园体制改革取得了重大进展, 积累 了一批可复制可推广的制度和经验(彭福伟, 2018; 田俊量, 2018; 黄宝荣等, 2018)。整体而言, 改革成 功经验可以总结为四个方面。

\section{1 高层引领与改革创新}

国家公园体制试点和改革的成功首先得益于 高层领导的重视与引领, 通过改革创新推动整体进 展。习近平总书记高度重视国家公园建设, 多次发 表重要讲话和作出批示, 引领国家公园体制改革方 向, 推动试点和制度建设工作不断深入。例如, 2016 年, 在中央财经领导小组第12次会议上, 习近平指 出“要着力建设国家公园, 保护自然生态系统的原 真性和完整性, 给子孙后代留下一些自然遗产。要 整合设立国家公园, 更好保护珍稀濒危物种, 要研 究制定国土开发保护的总体性法律, 更有针对性地 制定和修订有关法律法规”。在总书记的高度重视 和关心下，国家发展改革委协调各部门和咨询专家， 统筹推进各项改革任务, 国家公园体制改革的各项
工作有条不紊地进行，并且进展迅速、成果丰硕， 已成为生态文明建设综合性改革的标杆。

\section{2 试点先行和动态调整}

国家公园对于我国来说是新生事物，在试点、 争论和探索的过程中逐步达成共识并不断深化。中 国有几千年的文明史，人和自然长期共存，即便是 在西部自然条件极其恶劣的地区都有人长期居住, 而东部地区更是人口密集。如何在新的生态保护格 局下处理人和自然的关系，是国家公园建设面临的 一个重大挑战。

我国建设国家公园的制度背景与欧美国家有 较大差异, 后者的成功经验可参考但难以复制。在 缺少成熟经验借鉴的情况下，倡导地方首创精神， 实行试点先行十分必要。在开展试点的同时，国家 发展改革委还成立了国家公园体制试点专家组, 邀 请专家学者参与各试点的调研、实施方案编制与监 督评估, 并参与国家公园体制改革总体方案的咨询, 取得了良好效果。比如关于国家公园和自然保护地 的关系，就是通过实践，反复讨论、咨询，最终在建 立国家公园体制总体方案中, 确立了以国家公园为 代表的自然保护地体系的定位。

\section{3 问题导向和顶层设计}

坚持问题导向是我国平衡发展与保护关系的 重要经验, 加强顶层设计保证了国家公园试点在重 点突破基础上的统筹推进，实现系统保护的目标任 务。在生态文明建设的总体目标下，国家公园体制 试点把管理体制、责权关系，以及协调、监管、资 金、保护、参与机制等重要问题作为改革重点任务, 进行深入探讨和试验，力图把问题导向与目标导向 有机结合。

正是基于问题导向的试点和研究，并结合目标 导向，使国家公园体制改革的顶层设计有了科学依 据。这些成果也充分反映在2017年出台的《建立国 家公园体制总体方案》中。

\section{4 利益相关方参与和改善治理体系}

国家公园体制改革从一开始就十分重视利益 相关方参与, 并把改善治理体系、提高治理能力作 
为重要举措。

首先, 政府相关部门参与。国家发展改革委联 合环保部、住建部、国家林业局共同管理试点工作, 并根据专业特点分工负责不同试点, 充分发挥了各 部门的作用。

其次, 充分调动各利益相关方的积极性, 促进 广泛参与。例如, 早在2014年10月, 由国务院发展 研究中心、世界自然保护联盟、世界自然基金会等 机构就联合组织召开了 “生态文明建设与国家公园 体制论坛”, 各政府部门充分利用了这个平台, 交 流彼此看法, 寻求改革共识。此外, 全国政协及相 关机构也都通过调研、撰写咨询报告, 为国家公园 体制改革贡献智慧。保尔森基金会、世界自然基金 会、桃花源生态保护基金会等国内外组织也分别与 国家发展改革委和试点单位签署了国家公园建设 合作协议或合作谅解备忘录, 共同参与到国家公园 体制试点和建设中。

第三, 组织开展多种形式的研究项目, 包括国 家公园治理体系、空间规划、法律法规、资源管理 体制、财政事权划分与资金机制、国际案例分析等。 这些项目为国家公园体制建设提供了科学支撑。

第四, 媒体宣传也发挥了重要作用。自十八届 三中全会提出建立国家公园体制后, 国家公园建设 成为各大媒体关注的热点话题, 引发了社会各界的 讨论; 主管部门也利用各种媒体向社会公众传播国 家公园坚持生态保护第一、国家代表性和全民公益 性的建设理念。

\section{面临的问题与挑战}

尽管取得了不少成绩，但由于历史积累下的问 题、各方面对新生事物理解上的差异、我国面临的 社会经济快速转型以及新时代生态文明建设和高 质量发展与保护的要求，国家公园建设还需要克服 众多困难和挑战。

\section{1 人口众多、分布广泛, 促进人与自然和谐发展 面临巨大挑战}

我国具有重要保护价值的自然生态系统及周 边地区往往分布着大量人口。以自然保护区为例, 截至 2014年底, 全国 1,657 个已界定范围边界的自 然保护区内共分布有居民 1,256 万人(徐网谷等, 2016)。如果将周边以自然保护区资源为重要生计来 源的社区包含在内, 人口规模更大。而且, 自然保 护地及周边通常也是我国集中连片贫困区, 面临较 大的脱贫减贫压力。

以最先开展的十个国家公园体制试点区为例, 多分布大量人口(表1)。一方面, 国家公园实施严格 的保护，但保护过程中如何实现人与自然的和谐, 如何保障原住民利益、开发替代生计和促进社区发 展，仍面临严峻挑战; 另一方面，大量人口的长期 资源开发，特别是近几十年来的高强度利用，已造 成我国具有完整性和原真性的自然生态系统所剩 不多, 国家公园建设将面对较大的生态修复压力。

\section{2 土地权属复杂, 获取土地管理权困难}

我国大量需要保护的自然区域的土地所有权

表1 十个国家公园体制试点区人口分布情况

Table 1 Population distribution in the ten pilot areas of the national park system

\begin{tabular}{lllll}
\hline $\begin{array}{l}\text { 试点区域 } \\
\text { Pilot areas }\end{array}$ & $\begin{array}{l}\text { 乡镇数 } \\
\text { Number of township }\end{array}$ & $\begin{array}{l}\text { 行政村数 } \\
\text { Number of administrative villages }\end{array}$ & $\begin{array}{l}\text { 户数 } \\
\text { Households }\end{array}$ & $\begin{array}{l}\text { 人口 } \\
\text { Population }\left(\times 10^{4}\right)\end{array}$ \\
\hline 三江源 Three River Source & 12 & 53 & 16,621 & 6.40 \\
神农架 Shennongjia & 8 & - & - & 8.00 \\
大熊猫 Giant Panda & 160 & - & - & 23.2 \\
东北虎豹 Northeast Tiger Leopard & 19 & 417 & 37,724 & 9.30 \\
钱江源 Qianjiangyuan & 4 & 19 & - & 0.97 \\
武夷山 Wuyishan & 5 & 25 & - & 3.00 \\
南山 Nanshan & 6 & 33 & - & 2.36 \\
普达措 Potatso & - & - & 429 & 0.23 \\
祁连山 Qilianshan & 53 & 256 & - & 8.80 \\
长城 Great Wall & - & - & 4,119 & 0.79 \\
合计 Total & - & - & - & 63.05 \\
\hline
\end{tabular}

注: 2019年1月23日，中央全面深化改革委员会审议批准的“海南热带雨林国家公园体制试点”未列入。

Note: The "Hainan Tropical Rainforest National Park System Pilot", which was reviewed and approved by the Central Committee for Comprehensive Deepening Reform in January 23, 2019, was not included. 
为集体所有。以钱江源、武夷山和南山 3 个国家公 园体制试点区为例, 集体土地占试点区面积的比例 分别高达79.6\%、71.3\%和58.5\% (表2)。同时，很多 国有土地被集体承包经营, 如三江源国家公园体制 试点区土地虽为全民所有, 但草地使用权全部被承 包到牧户。而且, 很多自然区域存在土地权属不清 的问题，土地所有权、承包经营权、使用权、管理 权、收益权混乱(沈兴兴, 2018)。除财政能力外, 国 家公园管理机构获取公园内土地管理权面临很多 困难。同时，在土地三权分置改革的新背景下，怎 样考虑国家公园未来土地制度的改革，也将是新的 挑战。

\section{3 重组自然保护地体系将面临各类利益冲突和} 阻力

未来我国的国家公园建设, 很大程度上将通过 整合现有保护地来完成, 这一过程中难免会遇到各
种阻力。一方面新的国家公园建立将涉及到众多机 构和人员的归并整合、财权事权调整和人事变动, 影响一些机构和个人的利益，存在抵制的阻力。另 一方面很多具有国家代表性的自然和文化遗产，同 时具有很高的景观和美学价值, 在未建国家公园之 前, 已经是知名的旅游景点。由于国家公园实施最 严格的保护，并强调全民公益性，可能会对旅游收 入造成一定的影响，这使得一些地方政府和旅游从 业者缺少参与国家公园建设的积极性。

\section{4 地方治理能力薄弱, 存在社会冲突隐患}

当前，我国无论是已有的各类保护地，还是国 家公园体制试点区，在区域设立、划定边界、功能 分区和管理中，政府均占绝对主导地位，缺少完善 的治理结构，市场和社会公众参与不足，独立的咨 询评估机制普遍缺乏。已有的关于鼓励社会投入和 公众参与的法规规定基本上都是原则性的，没有明

表2 十个国家公园体制试点区土地所有权结构

Table 2 Land ownership structure in the ten pilot areas of the national park system

\begin{tabular}{llll} 
试点区域 & $\begin{array}{l}\text { 总面积 } \\
\text { Pilot areas }\end{array}$ & $\begin{array}{l}\text { 国有土地 } \\
\text { Nation-owned land (\%) }\end{array}$ & $\begin{array}{l}\text { 集体土地 } \\
\text { Collective land (\%) }\end{array}$ \\
\hline 三江源 Three River Source & 123,100 & 100 & 0 \\
神农架 Shennongjia & 1,170 & 85.8 & 14.2 \\
大熊猫 Giant Panda & 27,134 & - & - \\
东北虎豹 Northeast Tiger Leopard & 14,926 & 91.4 & 8.6 \\
钱江源 Qianjiangyuan & 252 & 20.4 & 79.6 \\
武夷山 Wuyishan & 982.59 & 28.74 & 71.3 \\
南山 Nanshan & 635.94 & 41.5 & 58.5 \\
普达措 Potatso & 300 & 78.1 & 21.9 \\
祁连山 Qilianshan & 50,200 & - & - \\
长城 Great Wall & 59.91 & 50.61 & 49.39 \\
\hline
\end{tabular}

表3十个国家公园体制试点区中包含的各类保护地数量

Table 3 Number of different types of protected areas in the ten pilot areas of the national park system

\begin{tabular}{lllllll}
\hline 试点区域 & $\begin{array}{l}\text { 自然保护区 } \\
\text { Pilot areas }\end{array}$ & $\begin{array}{l}\text { 风景名胜区 } \\
\text { Scenic spots }\end{array}$ & $\begin{array}{l}\text { 森林公园 } \\
\text { Forest parks }\end{array}$ & $\begin{array}{l}\text { 湿地公园 } \\
\text { Wetland parks }\end{array}$ & $\begin{array}{l}\text { 地质公园 } \\
\text { Geoparks }\end{array}$ & $\begin{array}{c}\text { 其他 } \\
\text { Others }\end{array}$ \\
\hline 三江源 Three River Source & 4 & 0 & 0 & 0 & 0 & 0 \\
神农架 Shennongjia & 2 & 1 & 1 & 1 & 0 & 1 \\
大熊猫 Giant Panda & 42 & 13 & 14 & 0 & 5 & 7 \\
东北虎豹 Northeast Tiger Leopard & 7 & $/$ & 3 & 1 & 0 & 1 \\
钱江源 Qianjiangyuan & 1 & 1 & 1 & 0 & 0 & 0 \\
武夷山 Wuyishan & 1 & 1 & 1 & 0 & 0 & 1 \\
南山 Nanshan & 1 & 1 & 1 & 0 & 0 & 0 \\
普达措 Potatso & 1 & 1 & 0 & 1 & 0 & 0 \\
祁连山 Qilianshan & 3 & 0 & 1 & 1 & 0 & 1 \\
长城 Great Wall & 0 & & & & 0 \\
\hline
\end{tabular}


确的权利义务规定, 缺乏可操作的程序和制度保 障。政府绝对主导的治理模式, 面临管理成本高、 国家公园的建设管理与周围的民众矛盾较大、利益 相关方的权益得不到保障等问题。

\section{5 未形成多元资金投入机制，普遍面临资金短 缺问题}

目前，原有的各类保护地资金投入不足，现行 国家公园体制试点的财政资金也十分有限, 没有形 成稳定持续的投入机制。尽管一些社会资本有较强 的投资意愿，但由于尚未建立规范的特许经营、特 许保护等制度, 不敢贸然介入。各级试点区开展集 体土地赎买和流转、企业退出、矿业权退出、生态 移民等均需大量资金, 远超地方政府承受能力, 因 此普遍存在资金短缺问题。

\section{6 专业化、差别化、精细化的管理能力薄弱}

在现行的自然保护区、森林公园、湿地公园, 以 及国家公园体制试点区范围内，与专业化、差别化、 精细化的管理措施存在明显差距。保护地管理普遍 面临自然生态本底不清楚、管理目标不明确、管理 方法不规范, 以及缺乏现代化的监测管理设备、科 学合理的年度管理计划以及专业化管理人员等问 题，使保护地管理质量和效率不高。

\section{3 未来展望与建议}

从国家公园体制试点和改革实践取得的成效 看，国家公园建设在党中央、国务院的坚强领导下， 正走在正确的改革道路上。对国家公园建设的未来, 一方面我们充满信心, 另一方面要实事求是、按科 学规律办事, 尽力而为、量力而行, 保持好改革的 战略定力、节奏和力度, 一步一个脚印, 使人民利 益和公共利益得以最大化, 真正实现人与自然和谐 发展。

我们需要充分总结成功的经验, 明确我们做对 了什么以及需要始终坚持的做法, 按照《建立国家 公园体制总体方案》的要求，坚持正确的国家公园 建设理念。同时, 也要正视存在的问题和挑战, 辩 证地看待保护与发展的关系, 避免走回头路, 在国 家公园管理职能转隶的新体制下, 为改革开放再出 发积蓄力量, 理顺各方面关系和听取不同意见, 尊 重科学规律, 不断创新工作方法, 积极推动利益相 关方有序参与, 完善治理体系, 用严格的制度规范 国家公园的设立与管理。

\section{1 统筹推动以国家公园为主体的自然保护地体 系建设}

国家公园体制建设必须考虑改革和发展的宏 观背景, 特别是在我国处于社会经济转型期、资源 环境平台期, 以及外部环境不确定性增加的大环境 下，需科学谋划国家公园及各类保护地的长期发 展。我们要考虑的不仅仅是在2020年依法依规设立 第一批国家公园, 还要有更长远的目标和规划。

首先，国家公园建设应该坚持几个基本原则, 即坚持依法办园、科学办园、民主办园和开放办园, 做到保护优先和以人民为中心的有机统一。只有坚 持这些原则, 国家公园才能实现自然生态系统的原 真性、完整性和系统性保护，才能让人民拥有更多 获得感, 人与自然和谐共生, 实现国家所有、全民 共享、世代传承的国家公园建设目标。

第二, 要做到六个相互结合, 即顶层设计与摸 石头过河结合, 中央和地方结合, 政府、市场与社 会结合, 理论和实践结合, 短期和长期结合, 国际 经验与国内改革创新结合。国家公园的成功也不能 仅仅依靠顶层设计, 而是要处理好上述几大关系。 建设国家公园没有现成的灵丹妙药, 实现目标的答 案就在我们改革开放的实践行动中, 在科学理论的 指导和具体实践互动中。我们要建立一个具有专业 化、差异化、精细化特点的管理体系, 也需要通过 实践逐步完善。因此，建议把试点作为未来设立国 家公园的重要步骤和前提条件, 并加强对试点过程 的独立评估。

第三，要做好国家公园体制改革的中长期规 划。要系统制定国家公园体制改革的路线图、时间 表、优先序, 理顺各类保护地的关系, 按照决策科 学透明、尊重历史传承、便于国际比较、区分保护 目标的原则, 确定科学的分类标准, 加快归并整 合。国家公园体系的建立并不一定越快就越好, 而 是要以提高保护质量和突出系统保护为核心, 体现 国家公园保护的主体价值和国家代表性的标杆作 用, 引领整个自然保护地的高质量发展与保护。

\section{2 加快推进国家公园和自然保护地立法进程}

加快《国家公园法》立法进程, 深化管理体制 机制改革, 明确各相关方法律责任, 依法设立国家 公园。在当前的生态文明体制改革和建设过程中, 包括国家生态文明试验区、国家公园体制试点等工 作，都不可避免地遇到各种行政干预。为了减少国 
家公园设立过程中的行政干预，建议在拟制定的 《国家公园法》中明确设立国家公园的权限、程序 及重要制度的安排。同时, 结合我国自然保护地分 类和完善治理体系的要求, 同步考虑自然保护立法 体系设计, 统筹制修订相关法律法规, 立改废释并 举, 包括推动《自然保护地法》立法及相关管理条 例的修订工作等。

\section{3 构建多元共治的国家公园治理体系}

国家公园建设需吸取我国自然保护区“先画圈 后保护”所带来的管理质量不高、保护与发展矛盾 突出等方面的教训, 充分重视利益相关方参与, 建 立现代化治理体系, 实现多元共治, 促进人与自然 和谐发展。我们的研究发现, 国内外做得较好的流 域治理、区域治理，都具备以下四个相互结合的关 键机制: 一是建立统筹决策机制，在中央统筹领导 下，逐步建立中央和地方政府、社区、行业协会、 公益组织等相关方参与的委员会或理事会制度, 保 障其决策权和监督权。二是明确管理执行机制, 由 各级林业和草原局/国家公园管理局承担。三是依托 科学咨询和评估机制, 由独立的科学委员会来执行, 为规划、保护和开发策略、绩效评估等提供科学支 撑; 四是完善社会参与机制, 重点确保社会有效参 与，保障相关方的基本权益。

\section{4 鼓励社会和公益组织参与国家公园建设与管理}

国家公园建设需要大量资金支撑, 但未来5-10 年我国经济将面临下行压力, 资金短缺可能成为未 来我国国家公园建设面临的一大挑战。但另一方面, 社会公益资金快速增长，许多社会公益组织都有很 强的参与国家公园建设的意愿。同时，在中国特色 国家治理体系下，非国家行为体的作用也在增强。 在这一背景下，应制定相关制度促进各类公益组织 和资金的参与。比如在国家公园立法中, 明确公益 组织参与建设和管理的法律地位及可参与的工作 范围; 建立特许经营和保护制度, 形成良性的公益 组织鼓励和保障机制; 发挥公益组织在推动社区发 展、科普和自然教育方面的作用等。

\section{5 探索建立国家公园生态产品价值实现机制}

为了保障国家公园提供重点生态产品和服务, 需建立机制让生态保护者获益, 把保护和发展协调 起来, 在守住绿水青山的同时, 收获金山银山, 走 向保护优先、绿色发展的道路。一是建立国家公园
生态补偿制度, 加强对国家公园内及周边由于保护 而发展受限地区的财政转移支付和生态补偿。二是 建立国家公园产品标识体系, 发展生态友好型经济 及产业, 给符合国家公园功能定位和质量标准的产 品授予标识，使其获得明显的绿色价值提升和更好 的市场销售前景。三是探索建立生态产品市场化机 制，明确生态产品产权归属，建立生态产品价值核 算、市场创建、定价和交易机制，使生态保护者能 通过市场手段获取经济收益。四是打造生态产品交 易平台，充分利用互联网、物联网、大数据等，有 效降低生态产品的成本和市场准入门槛，促进生态 产品和服务市场的繁荣。

\section{参考文献}

Huang BR, Wang Y, Su LY, Zhang CL, Cheng DW, Sun J, He SY (2018) Pilot programs for national park system in China: Progress, problems and recommendations. Bulletin of Chinese Academy of Sciences, 33, 76-85. (in Chinese with English abstract) [黄宝荣, 王毅, 苏利阳, 张丛林, 程多 威, 孙晶, 何思源 (2018) 我国国家公园体制试点的进 展、问题与对策建议. 中国科学院院刊, 33, 76-85.]

Peng FW (2018) Progress and outlook of national park system reform. China Institutional Reform and Management, (2), 46-50. (in Chinese) [彭福伟 (2018) 国家公园体制改革的 进展与展望. 中国机构改革与管理, (2), 46-50.]

Shen XX (2018) Supply-side structural reform research on governance models of Chinese national nature reserve. Wetland Science, 16, 24-29. (in Chinese with English abstract) [沈兴兴 (2018) 国家级自然保护区治理模式的 供给侧结构性改革研究. 湿地科学, 16, 24-29.]

Tian JL (2018) Ideas and explorations of Three-River-Source National Park. Forestry Construction, (5), 189-196. (in Chinese) [田俊量 (2018) 三江源国家公园的理念和探索. 林业建设, (5), 189-196.]

Wang Y (2017) Practice and innovation for overarching institution design of China's national park. Biodiversity Science, 25, 1037-1039. (in Chinese) [王毅 (2017) 中国国 家公园顶层制度设计的实践与创新. 生物多样性, 25, 1037-1039.]

Xu WG, Gao J, Xia X, Zhou DQ, Li ZL, Jiang KM (2016) Distribution of community residents in nature reserves and its impacts on the reserves in China. Journal of Ecology and Rural Environment, 32, 19-23. (in Chinese with English abstract) [徐网谷, 高军, 夏欣, 周大庆, 李中林, 蒋明康 (2016) 中国自然保护区社区居民分布现状及其影响. 生 态与农村环境学报, 32, 19-23.]

(责任编委: 马克平 责任编辑: 周玉荣) 